\title{
The Comparison between Free Thyroxine and Thyroid-Stimulating Hormone Levels on Melasma Severity: A Cross-Sectional Study
}

\author{
Yusnita Rahman ${ }^{1}$, Roro Inge Ade Krisanti ${ }^{1}$, Wismandari Wisnu ${ }^{2}$, Irma Bernadette S. Sitohang ${ }^{1 *}$ \\ ${ }^{1}$ Department of Dermatology and Venereology, Faculty of Medicine, Universitas Indonesia, Dr. Cipto Mangunkusumo National \\ Central General Hospital, Salemba, Jakarta, Indonesia; ${ }^{2}$ Department of Internal Medicine, Faculty of Medicine, Universitas \\ Indonesia, Dr. Cipto Mangunkusumo National Central General Hospital, Salemba, Jakarta, Indonesia
}

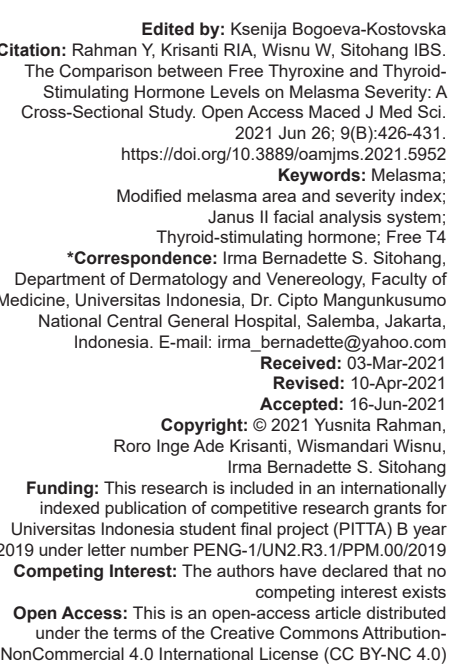

Edited by: Ksenija Bogoeva-Kostovska Citation: Rahman Y, Krisanti RIA, Wisnu W, Sitohang IBS The Comparison between Free Thyroxine and ThyroidStimulating Hormone Levels on Melasma Severity: A
Cross-Sectional Study. Open Access Maced J Med Sci. 2021 Jun 26; 9(B):426-431.
https://doi.org/10.3889/oamjms.2021.5952
Keywords: Melasma; 2021 Jun 26; 9(B):426-431.
https://doi.org/10.3889/oamims.2021.5952
Keywords: Melasma; Modified melasma area and severity index; Thyroid-stimulating hormone; Free T4 *Correspondence: Irma Bernadette S. Sitohang Department of Dermatology and Venereology, Faculty of edicine, Universitas Indonesia, Dr. Cipto Mangunkusumo National Central General Hospital, Salemba, Jakarta, Indonesia. E-mail: irma_bernadette@yahoo.com Received: 03-Mar-202 Accepted: 16-Apr-2022 Copyright: @ 2021 Yusnita Rahman, Roro Inge Ade Krisanti, Wismandari Wisnu, Irma Bernadette S. Sitohan Funding: This research is included in an internationally indexed publication of competitive research grants for Universitas Indonesia student final project (PITTA) B year 2019 under letter number PENG-1/UN2.R3.1/PPM.00/2019 Competing Interest: The authors have declared that no Open Access: This is an open-access article distributed under the terms of the Creative Commons Attribution under the terms of the Creative Commons Attribution-
onCommercial 4.0 International License (CC BY-NC 4.0)

\section{Abstract}

BACKGROUND: Melasma has been suspected to be linked with levels of thyroid hormone. There is no study that explains the association between thyroid hormone levels with melasma severity.

AIM: This study aims to find the discrepancies in the levels of thyroid hormone in varying severity of melasma using two different measurement techniques.

METHODS: Subjects were chosen consecutively from the dermatology clinic at RSUPN Dr. Cipto Mangunkusumo hospital. Forty-eight patients participated in this study were categorized into mild melasma and moderate-severe melasma based on modified melasma area and severity index (mMASI) and Janus II measurement.

RESULTS: Statistically, mMASI measurement showed no significant association between varying melasma severity with levels of thyroid stimulating hormone and free T4 (FT4), $p=0.375$ and $p=0.208$, respectively. The Janus II examination using polarized light modality has a weak positive correlation with the serum FT4 level ( $r=$ $0.3 ; p=0.039)$. Weak correlation was also found between the two measurement strategies, Janus II and mMAS $(r=0.314 ; p=0.03)$

CONCLUSION: There are no significant differences observed in levels of thyroid hormone between subjects with varying degrees of melasma severity.

\section{Introduction}

Melasma is a form of hyperpigmentation disorder that presents around the forehead $(F)$, upper lip, cheeks, and chin (C) with characteristics such as a larger size of melanosome and a higher percentage of melanosome keratinocyte. Melasma is also known as "chloasma" and "mask of pregnancy" because of its high prevalence in pregnant women [1], [2]. Melasma often occurs in reproductive-aged women, with highest prevalent in age group of 20-50 years old. However, this condition is also known to occur in men. The prevalence of melasma is around $1.5-33.3 \%$ depending on population and geographical location [3]. In 2018, the prevalence of melasma in RSUPN dr. Cipto Mangunkusumo (RSCM) hospital Jakarta is $3.551 \%$ on women and $0.042 \%$ on men. There is a higher frequency of melasma found in women with Fitzpatrick III-V type of skin who lives in areas with high exposure of ultraviolet (UV) light, such as women living in East Asia (Japan, Korea, China), India, Pakistan, Middle East, Africa, and Indonesia [4], [5].
The etiopathogenesis of melasma is still unknown. However, several factors including the exposure of sunlight, pregnancy, hormonal factors, and genetic predisposition could play a role in the pathogenesis of melasma [3] Estrogen and progesterone are known to play important roles in the pathogenesis of melasma. In addition to the sex hormones, developing theory focuses more on the effect of thyroid hormone dysfunction toward melasma. The dysfunction of thyroid hormone production can either be in the form of autoimmune disease or thyroid gland disease such as hyperthyroidism. However, the mechanism of thyroid hormone in the pathogenesis of melasma is still unknown [6], [7], [8].

The existence of thyroid hormone receptor on skin proves that the skin is an extrathyroidal target of thyroid hormone. Higher level of thyroid hormone or hyperthyroidism causes oxidative stress and the release of pro-inflammatory cytokines which is then responded by the epidermal-melanin unit through melanogenesis, which plays a role in melasma pathogenesis [9], [10]. 
There have been several reports that described the association between melasma and thyroid hormone levels. For instance, Lutfi et al. reported that there were $58.3 \%$ of melasma patients also had a four-fold rise in serum T3, T4, and thyroid stimulating hormone (TSH) level compared to the normal population [11]. Similar result was also reported by Yazdanfar, who found that there was an increase of anti-thyroid peroxidase (antiTPO), T3, T4, and TSH level between melasma patients and control, although the result was not statistically significant [12]. Cakmak also reported that the level of serum free T4 (FT4), TSH, and anti-thyroglobulin was significantly higher in patients with melasma [13].

However, there were no studies that assess the association between levels of thyroid hormone and melasma severity. Therefore, this study aims to compare between FT4 and TSH levels on mild and moderatesevere melasma based on modified melasma area and severity index (mMASI) score which measures the area of melasma, severity of pigmentation, and lesion homogeneity. The determination of melasma lesion could also be known using Janus II facial analysis UV light and polarization light to analyze the pattern of hyperpigmentation on melasma.

\section{Methods}

A cross-sectional study was designed to compare the level of serum FT4 and TSH in patients with mild melasma and moderate-severe melasma. This study was performed in July 2019 with the approval from the ethical committee at our institution. To generate sample size, comparison of two independent means formula was used. The value for standard deviation and mean TSH level in mild melasma was obtained from the previous study [12]. The difference in mean between two groups was estimated to be 1.4 with $95 \%$ confidence interval $(\mathrm{Cl})$ and power chosen was 0.8. Consecutive sampling was used to select a total of 48 patients with ages ranging from 20 to 50 years that visited the dermatology and venereology clinic in RSCM hospital within the period of this study. To prevent thyroid hormone imbalances caused by external factors, patients with history of thyroid disease, drug usage that affects the thyroid (glucocorticoid, lithium, amiodarone, iodide, and octreotide), oral hormonal contraception in the past 1 year, hormone replacement therapy, and anticonvulsants, were excluded from this study. In addition, patients who have brown spots on the face which was preceded by red spots, brown spots caused by hydroquinone usage and pregnant women, were also excluded to avoid melasma misinterpretation.
Patients with a confirmed diagnosis of melasma were given oral and written explanation regarding the purpose and procedure of the study. Patients were then asked to fill in a form of agreement to join this study. Patients were classified into two groups; mild melasma and moderate-severe melasma according to the mMASI score, where score of 0-8 was considered as "mild" while any score above 8 was considered as "moderatesevere". mMASI is a method to evaluate the severity level of melasma by comparing the pigmentation in four areas of the face, which are the $F$, right malar region, left malar region, and $C$. Variables that are measure by mMASI scoring include the degree of darkness and involvement of the area [14], [15]. Darkness component was used to replace pigmentation and intensity in MASI scoring with modification mMASI [16]. However, assessment using mMASI is highly dependent on the operator; hence, a new objective examination to assess skin pigmentation was developed, which is the facial imaging analysis (e.g., Janus II facial analysis system). In this study, two modalities were used in the Janus II facial analysis system, which is the polarization light and UV light. The examination was done with digital photography and results are stated in percentage of the skin pigmentation. The level of serum FT4 and TSH was then measured in both groups of the patients.

The data are tabulated and a comparative analysis of serum FT4 and TSH levels with mild and moderate-severe melasma is done. In addition, this study also analyzes the level of serum FT4 and TSH with the result of Janus II facial analysis system scoring. The same method of analysis was done to know the association between mMASI and examination using Janus II facial analysis system.

\section{Statistical analysis}

Tabulation was performed on Microsoft Excel 2010, and data analysis on the program IBM SPSS 20. Data such as, socio-demographical data, clinical findings of melasma, level of serum TSH and FT4, the association of melasma severity with serum TSH and FT4 level, and the correlation between serum TSH and FT4 with the Janus II facial analysis system using UV light and polarization method were described using descriptive-statistic method. Categorical data were described using mean and standard deviation. Nominal data were described in proportion with the $\mathrm{Cl}$ level of $95 \%$ and a p-value. Bivariat analysis to search the comparison between serum FT4 and TSH with mild melasma and moderate-severe melasma was done using non-paired t-test. If the distribution of data is not normal, then a Mann-Whitney test is used. A correlation test was used to assess the association between FT4 and TSH level and Janus II facial analysis system scoring. 


\section{Results}

\section{Socio-demographical data}

Patients visiting the clinics were consecutively selected to obtain a total number of 48 eligible patients based on the aforementioned exclusion criteria. All patients participated in this study fulfilled the study criteria. No follow-up study is required. All patients were women, with age ranging from 20 to 50 years old. The median age was 44 years old; $83 \%$ of the subjects have a secondary level of education which is equal to junior high school and high school. Most of the subjects are stay-at-home parents (68\%). Each subject was exposed to sunlight for at least $10 \mathrm{~h}$ per day, 5 times per week. The description of the socio-demographic characteristics of subjects is provided in the following table (Table 1).

Table 1: The socio-demographical characteristics of subjects ( $n=48$ )

\begin{tabular}{ll}
\hline Characteristics & $\mathrm{n}(\%), \mathrm{n}=48$ \\
\hline Gender & \\
Women & $48(100)$ \\
Age & $44(23-50)$ \\
Level of education & \\
$\quad$ Advanced level & $2(4.2)$ \\
Secondary level & $39(81.3)$ \\
Primary level & $7(14.6)$ \\
Occupation & \\
Housewife & $33(68.8)$ \\
Employee & $3(6.3)$ \\
Others & $12(25)$ \\
UV exposure per week (10.00-16.00) & \\
4 days & $2(4.2)$ \\
5 days & $39(81.3)$ \\
6 days & $1(2.1)$ \\
7 days & $6(12.5)$ \\
Duration of UV exposure per week & \\
$\quad \leq 10 \mathrm{~h}$ & $36(75)$ \\
$>10 \mathrm{~h}$ & $12(25)$ \\
History of contraception usage & $33(68.8)$ \\
$\quad$ Yes (Hormonal) & $9(18.8)$ \\
Non-hormonal & $6(12.5)$ \\
No & $7(14.6)$ \\
Current usage of contraception & $41(85.4)$ \\
Yes (Non-hormonal) & \\
No & $47(97.9)$ \\
Blood pressure & $1(2.1)$ \\
$\quad<140 / 90$ & $3(6.2)$ \\
$\geq 140 / 90$ & $45(93.8)$ \\
History of black macule on pregnancy (hyperpigmentation) & $25(52.1)$ \\
Yes & $23(47.9)$ \\
$\quad$ No &
\end{tabular}

\section{Clinical findings of melasma}

Table 2 shows the melasma characteristics found on subjects, as well as the result of melasma scoring by mMASI and Janus II facial analysis system. The proportion of patients with mild melasma and moderate-severe melasma is equal.

Examination using mMASI was done by two examiners, (the author and the supervisor of this study). Reliability of the mMASI scoring was measured by the two-way mixed interclass coefficient test (ICC), with the ICC of $0.871(0.781-0.926)$ and $\mathrm{Cl}$ of $95 \%$. There is no significant difference between examinations done by the two examiners; therefore it is valid.
Table 2: Clinical findings of melasma on the subjects $(n=48)$

\begin{tabular}{ll}
\hline Characteristics & $\mathrm{n}(\%), \mathrm{n}=48$ \\
\hline Location of hyperpigmented macule & $48(100)$ \\
Centrofacial & $46(95.8)$ \\
Malar & $26(54.2)$ \\
Mandibular & $25(52.1)$ \\
Mixed & \\
Size of hyperpigmented macule & $3(6.3)$ \\
Lenticular & $42(87.5)$ \\
Lenticular-plaque & $1(2.1)$ \\
Lenticular-nummular & $2(4.2)$ \\
Lenticular-linear & \\
Wood lamp examination & $34(66.7)$ \\
Contrast & $2(4.2)$ \\
Not contrast & $14(29.2)$ \\
Mixed type & \\
mMASI score & $8.047 \pm 0.643$ \\
Melasma degree & $24(50)$ \\
Mild & $24(50)$ \\
Moderate-severe & \\
Degree of pigmentation janus polarization & $45(93.8)$ \\
High & $3(6.2)$ \\
Moderate & $1.063 \pm 0.122$ \\
Janus polarization score & $18(37.5)$ \\
Degree of pigmentation janus UV & $16(33.3)$ \\
High & $14(29.2)$ \\
Moderate & $0.27(0.1-0.5)$ \\
Mild & \\
Janus UV score & \\
UV: Ultraviolet, mMASI: Modified melasma area and severity index. &
\end{tabular}

The association of serum TSH and FT4 level with the severity degree of melasma measured by mMASI

The association between serum TSH and FT4 level with the degree of melasma is shown in Table 3. Data analysis shows that there is not enough evidence to prove the association between the level of serum TSH and FT4 and various degrees of melasma when measured using mMASI. ( $p=0.375$ and $p=0.208$ ).

Table 3: The association of melasma severity degree with serum TSH and FT4 level $(n=48)$

\begin{tabular}{|c|c|c|c|}
\hline \multirow[t]{2}{*}{ Parameter } & \multicolumn{2}{|c|}{ Degree of Melasma } & \multirow[t]{2}{*}{ p-value* } \\
\hline & Mild & Moderate-Severe & \\
\hline TSH & $1.584(0-6.155)$ & $1.231(0.287-4.273)$ & 0.375 \\
\hline FT4 & $0.91(0.84-1.18)$ & $0.945(0.79-2)$ & 0.208 \\
\hline
\end{tabular}

The correlation of serum TSH and FT4 level measured by Janus II facial analysis system with different parameter

Scores that were collected from the Janus II facial analysis system examination were tested for correlation with the level of serum TSH and FT4 level (Table 4). The result shows that correlation is only found between the level of serum FT4 and Janus polarization test, with a correlation coefficient $(r)$ of 0.3 and $p=0.039$.

Table 4: Correlation of Serum TSH and FT4 Level with the Janus II facial analysis system result $(n=48)$

\begin{tabular}{|c|c|c|}
\hline Parameter & $r$ & $p$-value ${ }^{*}$ \\
\hline TSH with Janus polarization & 0.076 & 0.607 \\
\hline TSH with Janus UV & 0.073 & 0.622 \\
\hline FT4 with Janus polarization & 0.3 & 0.039 \\
\hline FT4 with Janus UV & 0.243 & 0.095 \\
\hline
\end{tabular}

\section{Correlation between Janus II and mMASI} score in the mMASI darkness score assessment

Correlation test was done to the mMASI darkness score and Janus II facial analysis system 
examination. A weak positive correlation is found between mMASI score and Janus polarization light test, with a correlation coefficient score of 0.314 and $p<0.05$. Meanwhile, there is no correlation found between the Janus UV test and mMASI darkness score $(r=0.129)$.

\section{Discussion}

Sex hormones (e.g., progesterone and estrogen) contribute in the development of skin pigmentation, particularly the role of estrogen in the pathogenesis of melasma. Estrogen is known to stimulate tyrosinase in melanin synthesis [3], [17]. The level of these hormones is exceptionally high during reproductive age which makes melasma prone to occur during this period of time. Moreover, increased level of these sex hormones also occurs in pregnancy. Nevertheless, only $6.2 \%$ of the subjects were reported to experience melasma during their pregnancy period. Conscious with the effect of hormonal changes in melasma occurrence, none of the subject taking part in this study was using hormonal contraception

The level of education of most subjects is secondary level which is equal to junior high and high school. In addition, most of the subjects were stay-athome parents. Similar result was found in a previous study done by Melyawati [18]. The lack of knowledge could contribute into the development of melasma, possibly because of lack of sunscreen usage [18].

Most of the subjects were exposed to sunlight for at least 5 days per week with duration of approximately $10 \mathrm{~h}$ per week. Subjects were exposed to at least $2 \mathrm{~h}$ of sunlight in a day. However, the usage of sunscreen for each subject was not identified and acknowledged as one of this study's limitation. Chronic exposure of UV light is associated with higher incidence of melasma as UV light affects melanogenesis and it bonds with keratinocyte [17]. In this study, there are more than $50 \%$ of subjects with family history of melasma.

The face is an area of predilection for melasma. Based on its clinical features, Melasma is classified into three groups: Centrofacial, malar, and mandibular. All subjects in this study had centrofacial melasma. These findings were in accordance with previous studies that reported centrofacial $(65 \%)$ melasma as the most common clinical manifestation, followed by malar $(20 \%)$ and mandibular (15\%) [2]. Based on the deposition of melanin pigment, melasma is classified into epidermal, dermal, and mixed type. A simple way to detect different types of melasma is through wood lamp examination where pigment enhancement by wood lamp indicates epidermal melasma while non-enhanced indicates dermal melasma. The proportion of subjects with negative wood lamp examination results was much lower than those with positive results. This indicates that epidermal melasma is more common compared to dermal melasma. Confirming our findings, the previous study also reported that the dermal type of melasma is only found in 10-15\% of all melasma cases [2].

Previously, several studies [11], [12] had shown possible positive relationship between thyroid disorders and melasma occurrence. For instance, Yazdanfar [12] observed serum anti-thyroid peroxidase, $\mathrm{T}_{3}$, and TSH are higher in melasma patients than in control group. Hence, to further analyze thyroid-melasma relationship in this study, TSH and FT4 levels were measured to assess any possible thyroid abnormalities experienced by melasma patients. However, no thyroid abnormality was observed though subclinical hypothyroidism was found in $2.1 \%$ of the subjects and subclinical hyperthyroidism in $4.2 \%$ of the subjects.

Another prominent study in thyroid-melasma association, Lutfi, et al. [11], also reported the frequency of thyroid abnormalities (e.g., microsomal thyroid autoantibodies $>1: 100$ ) is greater in melasma patients $(58.9 \%)$ than in control group. However, limited thyroid abnormalities samples $(6.3 \%)$ in our study had made it impossible to conduct side by side analysis with study performed by Lutfi et al. [11] who had obtained higher thyroid abnormalities samples as their study was mainly focused on the correlation between thyroid disorder and melasma. For instance, Lutfi et al. reported significant increase in thyrotropin-releasing hormone-TSH test on groups with struma and a history of graves disease while we are unable to assess this relationship due to limited thyroid abnormalities samples. Moreover, TSH and FT4 serum levels, which have a higher diagnostic value of thyroid abnormalities, were not measured by Lutfi et al. as well.

In subjects with moderate-severe melasma, low level of TSH while high level of FT4 serum was observed. This condition depicts an overactive thyroid condition called hyperthyroidism. The previous studies had described an association between melasma and hyperthyroidism [9], [10]. Yet, the underlying mechanism of thyroid hormone in the pathogenesis of melasma remains unknown. However, thyroid hormone receptors can be found in the skin. This proves that the skin is an extrathyroidal target of thyroid hormone. Increased level of thyroid hormone or hyperthyroidism cause oxidative stress and the release of pro-inflammatory cytokines, which are then responded by the epidermal-melanin unit through melanogenesis as a step in the pathogenesis of melasma [10].

Despite robust theoretical evidence in supporting the association between hyperthyroidism and melasma occurrence, Çakmak, et al. [13] claimed that melasma might occur in both hyper and hypothyroid cases. They reported that the level of serum FT4 and $\mathrm{TSH}$ was significantly higher in the melasma group. These results may explain the pathogenesis of certain types of melasma is associated with different levels of thyroid hormone abnormality. Nevertheless, their study found no association between the mMASI score 
and level of thyroid hormone and auto-antibody which is also in accordance with the result obtained in this study [13]. Hence, it is highly likely that there is no association between thyroid hormone and the degree of severity of melasma based on mMASI score.

In this study, measurement using the Janus II facial analysis system resulted in a higher degree of severity, compared to examination by mMASI. Examination which uses optical instrument could measure the quantification of severity because it makes a comprehensive comparison of all areas in the face, not only from certain area [19].

A weak correlation was found between the Janus II facial analysis system polarization light measurement result and the darkness score based on mMASI with a significant $(p=0.038)$ correlation coefficient of $(r)=0.3$. Meanwhile, the examination done with UV light on the Janus II facial analysis system did not have a significant association with the darkness score based on mMASI $(p>0.05)$. Different lighting modalities have different purposes in the analysis of the face. UV light modality is best used in a dark room to measure lesions located in the epidermis, including keratin, sebum, porphyrin, and pigmentation. The weak correlation between the measurement by mMASI and the result on Janus II facial analysis system polarization is because of the higher ability of polarization light to detect pigmentation on subepidermal layer and its high sensitivity toward melanin, thus making the result similar to the darkness score on mMASI [20], [21].

The results above show that there is no significant association between the level of serum thyroid hormone and Janus UV examination result. On the other hand, there is a positive correlation between Janus polarization light examination and the level of serum FT4. The author has not found any previous study that examines the correlation between pigmentation examination using Janus instruments and the level of serum thyroid hormone. This result can be explained as polarization light has a higher penetration to deeper layers of the skin. For example, it can be used to evaluate vascular lesions underneath the epidermis. In addition, polarization light is highly sensitive to chromophore such as melanin, and therefore it is better in detecting hyperpigmentation lesion [20], [21].

This study helps to explain the association between thyroid hormone with the degree of severity of melasma, and in comparing Janus II facial analysis systems result in various degrees of severity of melasma. However, there is a limitation to this study, in which this study did not assess other risk factors of melasma beside the level of thyroid hormone. Researchers performing similar studies are encouraged to consider genetic factors and ethnicity to explore further correlation between melasma and thyroid level. In the future, this research hopes that Janus II facial analysis system can be used to evaluate the progress of melasma therapy.

\section{Conclusion}

In summary, there is no significant association observed between the level of serum TSH and FT4 in mild melasma and moderate-severe melasma when measured using mMASI. The examination result from Janus II facial analysis system polarization light has a weak positive correlation and is statistically significant with the level of serum FT4. Meanwhile, the examination result from Janus UV does not correlate and is not significant with the level of serum FT4.

\section{References}

1. Umborowati MA. Retrospective study: Diagnosis and therapy of melasma patients. Berkala IImu Kesehatan Kulit Kelamin. 2014;26(1):56-63.

2. Bagherani N, Gianfaldoni S, Smoller, B. An overview on melasma. J Pigment Disord. 2015;2(10):1-18.

3. Sarkar R, Arora P, Garg VK, Sonthalia S, Gokhale N, Sarkar R. Melasma update. Indian Dermatol Online J. 2014;5(4):426-35. https://doi.org/10.4103/2229-5178.142484 PMid:25396123

4. Sonthalia S, Sarkar R. Etiopathogenesis of melasma. J Pigment Disord. 2015;2(1):21-7.

5. Handel AC, Miot LD, Miot HA. Melasma: A clinical and epidemiological review. Braz Ann Dermatol. 2014;89(5):771-82. https://doi.org/10.1590/abd1806-4841.20143063 PMid:25184917

6. Ogbechie-Godec OA, Elbuluk N. Melasma: An up-to-date comprehensive review. Dermatol Ther. 2017;7(3):305-18. https://doi.org/10.1007/s13555-017-0194-1 PMid:28726212

7. Videira IF, Moura DF, Magina S. Mechanisms regulating melanogenesis. Braz Ann Dermatol. 2013;88(1):76-83. https:// doi.org/10.1590/s0365-05962013000100009 PMid:23539007

8. Martin NM, Smith KL, Bloom SR, Small CJ. Interactions between the melanocortin system and the hypothalamo-pituitary-thyroid axis. Peptides. 2006;27(2):333-9. https://doi.org/10.1016/j. peptides.2005.01.028

9. Mancini A, Di Segni CD, Raimondo S, Giulio O, Silvestrini A, Meucci E, et al. Thyroid hormones, oxidative stress, and inflammation. Mediators Inflamm. 2016;2016:6757154. https:// doi.org/10.1155/2016/6757154

10. Rozing MP, Westendorp RG, MaierAB, Wijsman CA, Frölich M, de Craen AJ, et al. Serum triiodothyronine levels and inflammatory cytokine production capacity. Age (Dordr). 2012;34(1):195-201. https://doi.org/10.1007/s11357-011-9220-x PMid:21350816

11. Lutfi RJ, Fridmanis M, Misiunas AL, Pafume O, Gonzalez EA Villemur JA, et al. Association of melasma with thyroid autoimmunity and other thyroidal abnormalities and their relationship to the origin of the melasma. $\mathrm{J}$ Clin Endocrinol Metab 1985;61(1):28-31. https://doi.org/10.1210/jcem-61-1-28

12. Yazdanfar A. Association of melasma with thyroid autoimmunity: A case-control study. Iran J Dermatol 2010;13:51-3.

13. Çakmak SK, Özcan N, Kiliç A, Koparal S, Artuz F, Cakmak A 
et al. Etiopathogenetic factors, thyroid functions and thyroid autoimmunity in melasma patients. Postepy Dermatol Alergol. 2015;32(5):327-30. https://doi.org/10.5114/pdia.2015.54742

PMid:26759539

14. Pandya AG, Hynan LS, Bhore R, Riley FC, Guevara IL, Grimes $\mathrm{P}$, et al. Reliability assessment and validation of the melasma area and severity index (MMASI) and a new modified MMASI scoring method. J Am Acad Dermatol. 2011;64(1):7883.e2. https://doi.org/10.1016/j.jaad.2009.10.051 PMid:20398960

15. Rodrigues $M$, Ayala-Cortés $A S$, Rodríguez-Arámbula $A$, Hynan LS, Pandya AG. Interpretability of the modified melasma area and severity index (mMMASI). JAMA Dermatol. 2016;152(9):1051-2. https://doi.org/10.1001/ jamadermatol.2016.1006

PMid:27144383

16. Majid I, Haq I, Imran S, Keen A, Aziz K, Arif T. Proposing melasma severity index: A new, more practical, office-based scoring system for assessing the severity of melasma. Indian J Dermatol. 2016;61(1):39-44. https://doi.org/10.4103/0019-5154.174024

PMid:26955093
17. Lee AY. Recent progress in melasma pathogenesis. Pigment Cell Melanoma Res. 2015;28(6):648-60. https://doi.org/10.1111/ pcmr. 12404

PMid:26230865

18. Melyawati. Korelasi Skor Telangiektasis Dengan Derajat Pigmentasi Lesi Melasma Studi Pada Buruh Perempuan Pabrik Sepatu Di Tangerang [Thesis]. Jakarta: Universitas Indonesia; 2014.

19. Bae Y, Nelson JS, Jung B. Multimodal facial color imaging modality for objective analysis of skin lesions. J Biomed Optics. 2008;13(6):064007. https://doi.org/10.1117/1.3006056

PMid:19123654

20. Marcum KK, Goldman ND, Sandoval LF. Comparison of photographic methods. J Drugs Dermatol. 2015;14(2):134-9. PMid:25689808

21. Nirmal B. Dermatoscopy image characteristics and differences among commonly used standard dermatoscopes. Indian Dermatol Online J. 2017;8(3):233-4. https://doi.org/10.4103/ idoj.idoj_319_16

PMid:28584773 